\title{
Görüntülü Mobil İletişimde Hologram Teknolojisinin Kullanımı
}

\author{
Şafak Kayıkçı ${ }^{1 *}$, Ahmet Yürekli \\ ${ }^{1}$ Bolu Abant İzzet Baysal Üniversitesi, Mühendislik Fakültesi, Bilgisayar Mühendisliği Bölümü, Bolu, Türkiye (ORCID: 0000-0002-3325-4731) \\ 2 Bolu Abant İzzet Baysal Üniversitesi, Mühendislik Fakültesi, Bilgisayar Mühendisliği Bölümü, Bolu, Türkiye (ORCID: 0000-0003-3010-6458)
}

(Bu yayın 26-27 Haziran 2020 tarihinde HORA-2020 kongresinde sözlü olarak sunulmuştur.)

(DOI: 10.31590/ejosat.779097)

ATIF/REFERENCE: Kayıkçı, Ş. \& Yürekli, A. (2020). Görüntülü Mobil İletişimde Hologram Teknolojisinin Kullanımı. Avrupa Bilim ve Teknoloji Dergisi, (Special Issue), 94-99.

$\ddot{O} \mathbf{z}$

Hologram teknolojisi günümüzde birçok değişik alanda kullanılmaktır ve uygulamalårda kolaylıklar sağlamaktadır. Lazer 1şınlarının karışımı ile oluşan hologramlar üç boyutlu bir görünüme sahiptir. Fen bilimlerinden medyaya kadar çok geniş alanlarda denenmektedirler. Çoğunlukla güvenlik amaçlı sektörlerde işlenen hologranlar, bir objenin lazerle gösterilmesidir. Günden güne yaygınlaşan bir teknolojisiyle, normal hayat düzeninde ve sanayide karşımıza çokça çıkabilecek üç boyutlu modellemedir. Bu projede akıllı telefonun veya tabletin üzerine yerleștirilebilen holografik piramit șeklinde cam bir materyal kullanılmıştır. İstemci sunucu mimarisiyle bir iletişim modeli kurulup görüntünün eş zamanlı olarak karşıdaki kişiye yansıtılması amaçlanmıştır. Bu tür görüntüler, camın üzerindeki piramit üzerindeki kenarların kırkbeş derece konumlandırılması ile çalışmaktadır. Uygulama sçeşitli ekran çözünürlükleri ve dpi ayarlarında test edilmiş, ölçeklendirme konusunda herhangi bir sorun yaşanmamıştır. Uygulama sunucu modunda yâda istemci modunda çalışırken cihaz performansını olumsuz etkilememiştir. Aktarılan görüntüde kalite kaybı görülmemiştir. Ancak sıkıştırma işlemlerinde kaliteden ôdün verilmediği için saniyedeki kare sayısında düşüklük yaşanmaktadır. İstemci ile sonucu arasında resimler base64 formatına çevirilerek iletilmektedir. Hernekadar görüntü geleneksel holografik piramitte piramidin merkezi etrafında yüzüyor gibi görünse de, görüntünün kendisì üç boyutlu değil iki boyutludur. Yapılan uygulama ile 3D görüntü elde edilmiştir. Böylece iyi bir gerçeklik duygusu kazanılmıștır. Önerilen sistem görüntülü iletişim, askeri eğitim, tıbbi eğitim, müze sergisi, mağaza sergisi ve temapark cazibe merkezleri gibi çeşitli alanlarda yaygın olarak uygulanabilir.

Anahtar Kelimeler: Hologram, Mobil İletisim, İnovasyon

\section{Use of Hologram Technology in Video Mobile Communication}

\begin{abstract}
Hologram that we encounter in many different areas today has managed to attract the attention of few of us, opens the doors of many technological facilities. It has a three-dimensional appearance, is a kind of mixture of laser beams and is used in many areas from the printing publication to the physics world. Hologram, which is a method developed for security purposes is the expression of a product or object through laser beams. It is a technology that is expanding more and more and it is a three-dimensional painting technique that we encounter in many places in everyday life and industry branches. In this project, a glass material in the form of a holographic pyramid which can be placed on the smartphone or tablet, is used. It is aimed to establish a communication model with the client server architecture and reflect the image to the other person simultaneously. These types of images work by positioning the edges on the pyramid on the glass fortyfive degrees. The application has been tested in various screen resolutions and dpi settings, and no problem has been encountered in scaling. While the application runs in server mode or client mode, it does not negatively affect device performance. There is no loss of quality in the transferred image. However, since compression is not compromised in quality, the number of frames per second is low. The pictures are converted to base64 format between the client and the result. Although the
\end{abstract}

\footnotetext{
* Sorumlu Yazar: Bolu Abant İzzet Baysal Üniversitesi, Mühendislik Fakültesi, Bilgisayar Mühendisliği Bölümü, İstanbul, Türkiye, ORCID: 00000002-3325-4731, safak.kayikci@ibu.edu.tr
} 
image seems to float around the center of the pyramid in the traditional holographic pyramid, the image itself is two-dimensional. A three dimensional image is obtained with the application. Thus, a good sense of reality is gained. The advanced framework can be applied extensively in different fields like video communication, military education, medical education, museum exhibition, store exhibition and theme park attractions.

Keywords: Hologram, Mobile Communication, Innovation

\section{Giriş}

Hologram terimi 1949'da, Macar doğumlu İngiliz elektrik mühendisi ve fizikçi Dennis Gabor tarafından icat edilmiştir [1]. Kendisi daha sonra bu yöntem üzerine 1971'de Nobel Fizik Ödülü'nü kazanmıştır. Hologram, Yunanca "bütün” anlamına gelen "holos" ve "mesaj" anlamına gelen "gramma" kelimelerinin birleşimidir. Bir mesajı oluşturmak için bir araya gelmek yani başka bir değişle bütün resmi oluşturmak anlamına gelmektedir. Geleneksel fotoğrafçılığın aksine, bir hologram üç boyutlu bir görüntüdür veya öyle bir izlenim verir. Işık kullanılarak, lazerler şeklinde yaratılarak gibi farklı farklı holografik teknikler vardır.

Günümüzde hologramlar kredi kartları, pasaportlar, markalı ürünler gibi çoğunlukla bir ürünün kimlik doğrulamasını ya da orijinal olup olmadığını göstermek için kullanılmaktadır. Bu hologramlar, bir lazer ışınının açılı bir ayna kullanılarak iki ayrı ışına bölünmesiyle oluşturulur. Bu daha sonra bir nesne 1şını ve bir yansıma 1şını oluşturur. Farklı yönlerde ilerlerken, her ikisi de diğer açılı aynalardan yansıtılır. Nesne 1şını daha sonra hologram görüntüsünü oluşturacak olan nesneden ve son olarak uç yüzeye (holografik plaka olarak da bilinir) yansıtılırken, yansıma ışını doğrudan plakaya yönlendirilir. Bu iki ışın bir araya geldikçe hologram oluşturulur. Bunların dışında en çok kullanılan hologram üretme teknikleri aşağıda incelenmiştir.

Çalışma prensibi olarak hologram teknolojisi üç boyutlu nesnelerin lazerler etkileşerek farklı ortamlara iletilmesidir. Gelen 1şık yarı saydam bir aynada ikiye ayrılır. Birincisi mercek tarafından nesneyi aydınlatır. Ikicincide aynadan iletilerek panele gider. Her iki ışı̆̆ın panelde yansımasıyla istenilen model yaratılır. İlaveten diğer bir lazer ise direk panele gönderilir. Bu iki lazerin birleşerek keşismesiyle panel üzerinde nesnenin 3D görüntüsü oluşur [2].

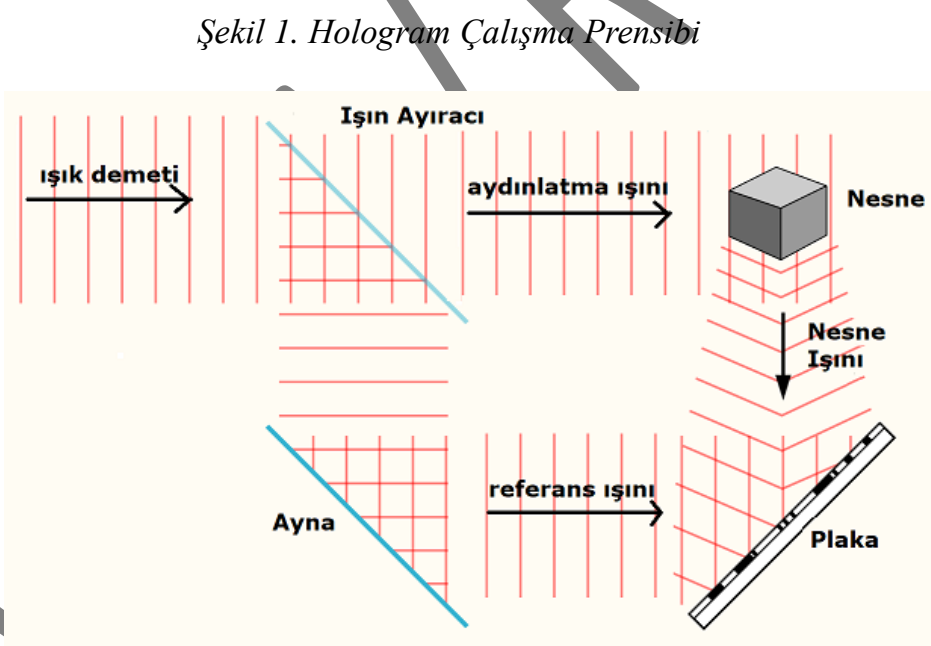

\section{Hologram Teknikleri}

\subsection{Pepper'in Hayaleti Etkisi}

Pepper'nn Hayaleti Etkisi (Pepper Ghost Effect) tiyatro, eğlence parkları, müzeler, televizyon ve konserlerde kullanılan bir yanılsama tekniğidir. Adı, 1862'de bir gösteride efekti popülerleştiren İngiliz bilim adamı John Henry Pepper'ın (1821-1900) adını almıştır. Yânılsamayı sahnelemek için kullanılan temel cihaz, iki görüntüyü izleyicinin bakış açısıyla birleştirmek için tersine çalışan bir optik ışın ayırıcıdır. Işın ayırıcı eleman tipik olarak büyük, düz bir sıradan cam tabakasıdır. Bir sahnenin görüntüsü cam yüzeyinden izleyicilere yansıtılır ve ikinci bir sahnenin görüntüsü camdan iletilir. Sahne aydınlatması, gözlemcilere görünmeyen camın kendisini değil sahneleri seçici olarak aydınlatmak için kontrol edilir [3]. Birleştirilmiş görüntü orijinaldir ve bir yanılsama değildir, yanılsama camı algılamayan seyirciden oluşur.

Pepper'ın Hayaleti Etkisi, uzun yıllardır denenen ve test edilmiş sağlam bir tekniktir. Büyük ölçekli projeksiyonlardan küçük sunumlara kadar değişik ölçeklerde kullanılabilir. Ancak, bu etikiyi oluşturmak için, kurulumu durgun ve ağır hale getiren yeterli bir pleksiglasa (holografik görüntüyü görüntülemek istediğiniz sahnede $45^{\circ}$ açıyla yerleştirilmiş) ihtiyaç vardır. Işık faktörlerine bağlıdır, yani genel ortamın projeksiyonu görünür yapacak kadar karanlık olmasını sağlamak hayati önem taşır. Gerçek hayattaki öğelerin konumlandırılması, hareketlerinin dikkatlice planlanması ve koordine edilmesi gerekir. Böylece sanatçı camla temas etmez veya görüntüyü bir şekilde gizlemez. 


\subsection{Holografik Duman Ekranı}

Holografik duman ekranı, hologramın yansıtılacağı bir ekranda olarak yapay olarak üretilen duman veya yarı saydam bir a $\breve{g}$ kullanarak çalışır. Bu durumda, projeksiyon altından ziyade arkadan gelir. Bu, bir hologram izlenimi veren spektral görüntü efektini yaratır. Hayalet gibi bir atmosfer ve etki yarattı̆̆ için sahne yapımları için etkili bir tekniktir [4]. Tiyatro tekniği olarak iyi kullanılmış ve kurulmuştur. Bunun yanında, ek malzemeler ve yarı saydam ağın arkasında ya da önünde bırakılacağı için gerçek dünyada iyi bütünleşmiş olmaz. Duman kullanıldığında, diğer karakterler görüntüyü kesintiye uğratarak, 1şık gibi çevre faktörleri açısından efekti olumsuz yapar.

\subsection{Holografik Ăglar}

Holografik dünyaya giren en son teknolojilerden biri, görüntüleri çeşitli renklerde görüntüleyen neredeyse şeffaf bir LED $1 s ̧ 1 k$ perdesi olan holografik ağlardır [5]. Bu LED'ler, 3D holografik tesir sunan görüntüler oluşturmak için programlanmıştır. Holografik ağlar, küçük ekranlardan renkli resimlerle binaları örtmeye kadar her şey için kullanılmıştır. Markalarını 1şıkta gôstermek isteyen şirketler için en uygun reklam firsatlarını sunarlar. Bir binanın büyüklüğüne kadar büyük ölçekli görüntüler oluşturma yeteneğine sahiptirler. Uygulamasında esneklik sağlar, düz veya kavisli olarak kullanılabilir. Nihai sonuç etkili olmasına rağmen, bir 3D görüntünün taklididir. İzleyici her zaman bir tür ekrana baktıklarının farkında olduğu için diğer varyantlar kadar sürükleyici değildirler.

\subsection{Holografik Dönen Ayna}

Holografik dönen ayna basit ama etkili bir çözümdür. Bir 3D görüntünün izlenimi, bir eğirme aynasının bir açıya yerleştirilmesi ve üzerine yüksek hızlı bir video yansıtılmasıyla verilir. Bu daha sonra ekranı oluşturmak üzere yansıtılır. Güney Kaliforniya Üniversitesi'nde geliştirilen çözüm, 3D holografik teknolojide yeni bir yenilik olarak tasarłanmışır [6]. 3D hologramın etkili bir optik yanılsamasını yaratır. Bir videonun sürümünü belirli bir ölçekte görüntüleme konusunda etkilidir. Ancak bu teknikte cihazın boyutu sinırlıdır, bu da kullanımını kısıtlar.

\subsection{Yarı Şeffaf OLED Ekranlar}

Son yıllarda, elektronik üretiminde şeffaf OLED ekranlara ciddi yatırımlar yapılmıştır. Bu yeni buluşlar, bir görüntü oluşturmak için elektrik akımına tepki veren organik ışık yayan diyotlarla dolu bir ekrana sahiptir. 3D etkiler açısından sonuç, 3D gibi görünen ve ekranda bir hologram yanılsaması yaratan bir 2D görüntüdür [7]. Piyasada çok yeni olan teknoloji hala hızla gelişmektedir. İçerik görüntülemenin çağdaş bir yolunu oluşturmaktadır, daha esnektir ve içerik görüntülemek için parlak bir platform sağlamaktadır. Görüntülenen görüntüler 3B görüntülerin 2B yanılsamasıdır. Yaklaş1 $\% 40$ şeffaflık düzeyi ile yani görüntü tamamen görünmez ve bazı arka plan görünmeye devam eder.

\section{Materyal ve Metot}

$\mathrm{Bu}$ projede akıllı telefonun veya tabletin üzerine yerleştirłlebilen holografik piramit şeklinde bir materyal kullanılmıştır. Bu hologram piramiti yansımayı "Pepper" in Hayaleti" etkisine benzer şekilde kullanır ve kendi içinde yüzen bir 3D hologram görünümü oluşturur. Bu tür görüntüler, camın üzerindeki piramit üzerindeki kenarların $45^{\circ}$ konumlandırılması ile çalışır. Kullanılan yansıtıcı materyal cam, plastik veya mika malzemeden yapılabilir. Standart bir ebatta üretime uygundur ve maliyeti düşüktür. Materyal, cihaz ekranında yansitılan imgeyi hologram olarak gösterir.

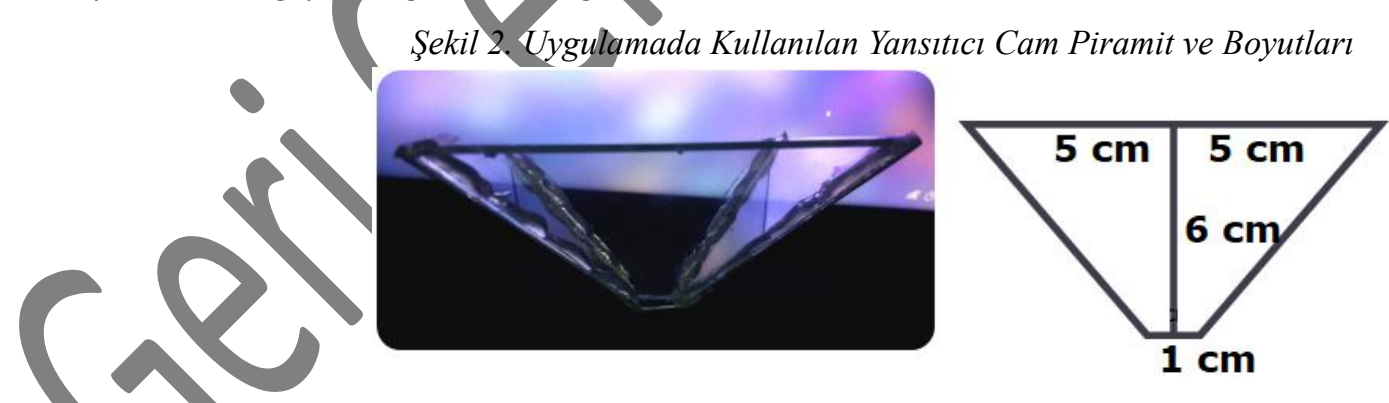

Çalışma için Android platformunda HoloCall isimli bir uygulama geliştirilmiştir. Uygulama üç ekrana sahiptir: Ana ekran kullanıcının seçimine göre sunucu veya istemci aktivitesini başlatan aktivitedir. Sunucu ekranı, ekran görüntüsünün alındığı ve istemciye gönderildiği aktivitedir. İstemci ekranı ise sunucudan ekran görüntülerinin alındığı, hologram imgesi haline getirildiği aktivitedir. 
Şekil 3. Uygulamanın Ana - İstemci - Sunucu Aktiveleri Tasarımları
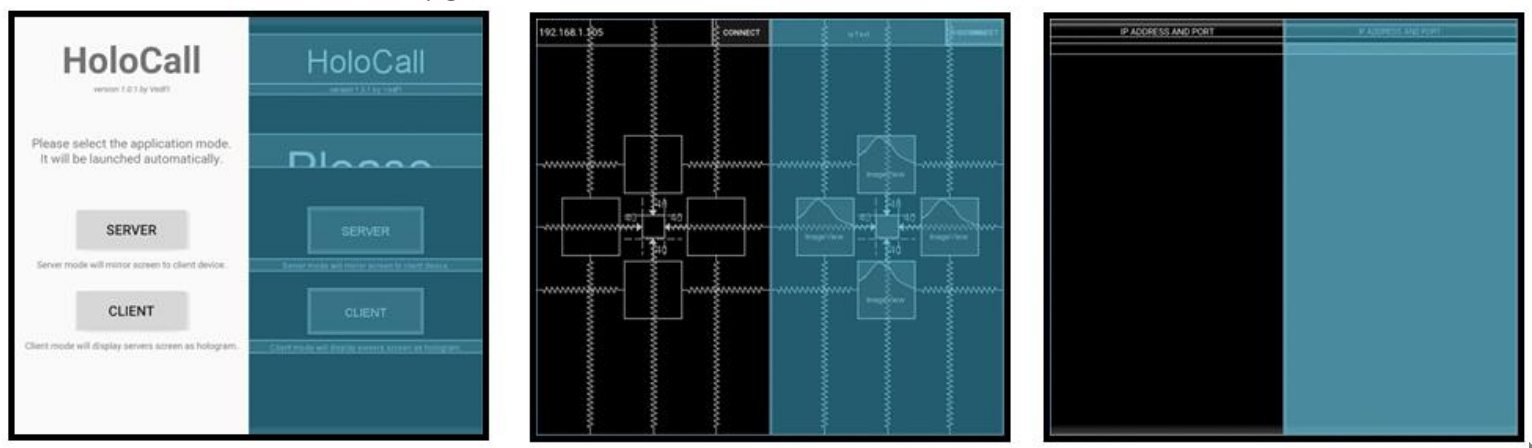

Şekil 3'de gösterildiği üzere, ana ekranda kullanıcının seçim yapabileceği iki adet düğme bulunmaktadır. Yapılan seçime göre istenen modda çalıştırılır. İstemci ekranında, kullanıcının sunucu adresini girebileceği bir alan, bağlantı kurmak için tıklanacak düğme ve hologram imgesinin oluşturulacağı ImageView [8] bileşeni yapıları bulunmaktadır. Sunucu ekranında, sunueunun çalıştığı IP adresi ve port bilgisinin gösterildiği bir metin bulunmaktadır. Uygulama sunucu olarak kullanılırken arka planda çalıştırılmalıdır.

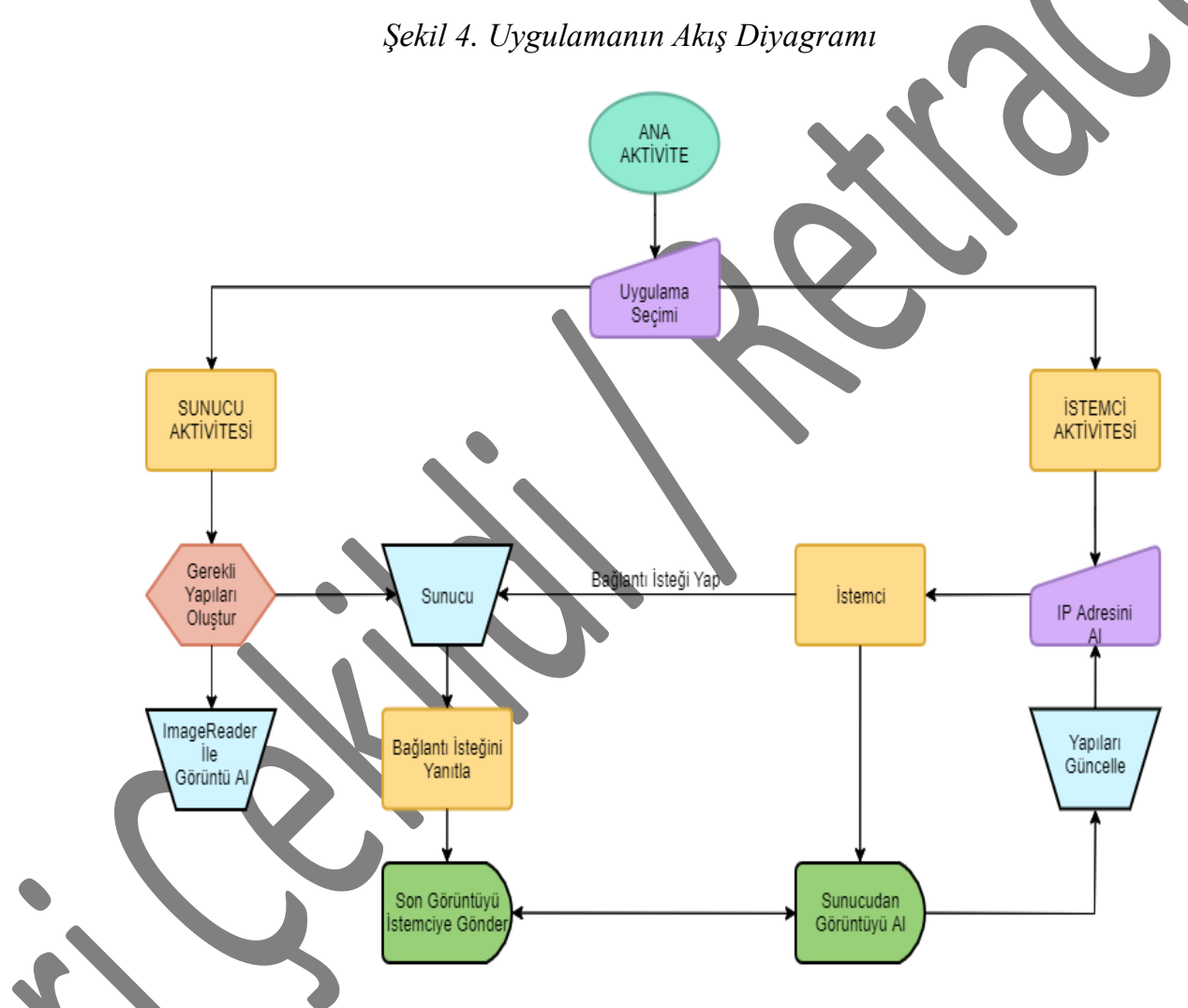

Holocall uygulaması sunucu kipinde çalışırken, ImageReader aracılığıyla bir görüntü elde edildiğinde, görüntü sıkıștırma yapılır. Sıkıştırma işlemi yapılırken ImageReader ile alınan görüntü Image objesi olarak kaydedilir. Kaydedilen obje YUV renk düzlemlerine ayrılır [9]. Ayrıştırılan düzlemdeki pikseller bir byte tampona aktarılır ve ARGB 8888 formatında bir Bitmap oluşturulur. Oluşturulan bitmap objesine byte tampondaki pikseller aktarılır ve bitmap objesine PNG formatında kayıpsız sıkıştırma yapılır. İstemciye bir görüntü gönderilmek istendiğinde, Base64 görüntü kodlama yapılır. Bu şekilde gönderilecek olan bitmap objesi metin(String) haline getirilmiştir. Holocall uygulaması istemci kipinde çalışırken; sunucudan kodlanmış bir görüntü metni alındıktan sonra, kod çözme yapılır. Alınan metin(String) bir bitmap objesine dönüştürülmüştür. Base64 ikili verilerin sadece ASCII karakterlerini kullanan ortamlarda iletilmesine ve saklanmasına olanak tanıyan bir kodlama şemasıdır [10]. Görüntülerin soket aracılığıyla gönderilebilmesi için metin haline getirilmesi gerekmektedir.

Holocall uygulaması çeşitli ekran çözünürlükleri ve dpi ayarlarında test edilmiş, ölçeklendirme konusunda herhangi bir sorun yaşanmamıştır. Ayrıca, uygulama çoklu pencere özelliğini desteklemektedir. İki cihaz ile görüntülü görüşme yapılırken, cihazlardan birinde Holocall uygulaması sunucu kipinde çalıştırılmıştır. Diğer cihazın kamerası kapatılmış ve Holocall uygulaması istemci kipinde başlatılarak sunucu cihaza bağlanmıştır. Şekil 6’te görüleceği üzere istemci cihaz üzerinde hologram imgesi başarıyla oluşturulmuştur. Uygulama her iki kipte de çalışırken cihaz performansını olumsuz etkilememiştir. Aktarılan görüntüde kalite kaybı görülmemiştir. Uygulama internet bağlantısı gerektirmeden çalışabilmektedir. Tek gereksinim sunucu ve istemci cihazların aynı ağda bulunmasıdır. Uygulamanın minimum gereksinimi API 21 olduğundan Android cihazların büyük çoğunluğunda çalışabilmektedir. 

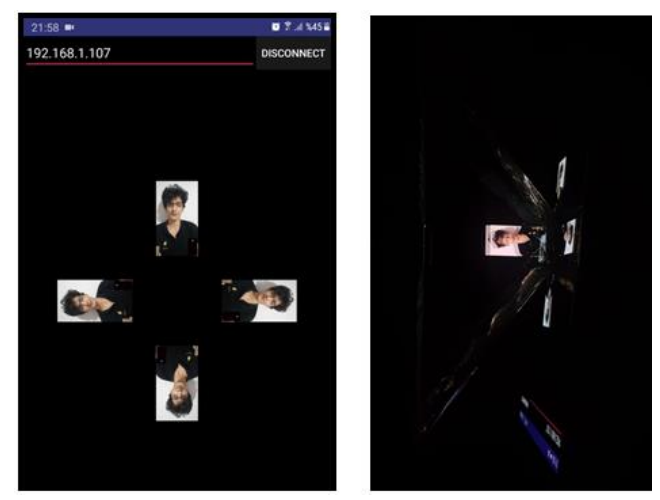

\section{Araştırma Sonuçları ve Tartışma}

Holocall görüntü kalitesini ve çözünürlüğü düşürmediği için görüntü alma ve aktarma işlemlerinde ele alınan veri büyüktür. Bu sebeple sıkıştırma işlemlerinde kaliteden ödün verilmediği için performans ve saniyedeki kare sayısı (FPS - frame per second) düşüklüğü yaşanmaktadır. FPS değeri cihaz donanımına, ağ performansına ve işletim sistemine bağlı olarak değişmektedir. FPS için gözlemlenen değer 7'dir. Görüntü aktarımı 3 ila 6 saniye arasında gecikmeli gerçekleşmektedir. Bu sorunları çözmek için uygulanabilecek adımlar şunlardır: ImageReader ile görüntü kaydedilirken kullanılan Bitmap objesi ARGB yerine RGB olarak ayarlanabilir. (A: pikseller için saydamlık değeri). Sunucudan istemciye bir görüntü gönderilirken Bitmap objesi görüntü kalitesi düşürülerek sıkıştırılabilir. MediaProjection ile oluşturulan sanal ekranın çözünürlügüü düşürülebilir.

Şekil 6. Uygulamanın Çalışma Anında Sunuc ve İstemci Bellekve Ağ Kullanımları
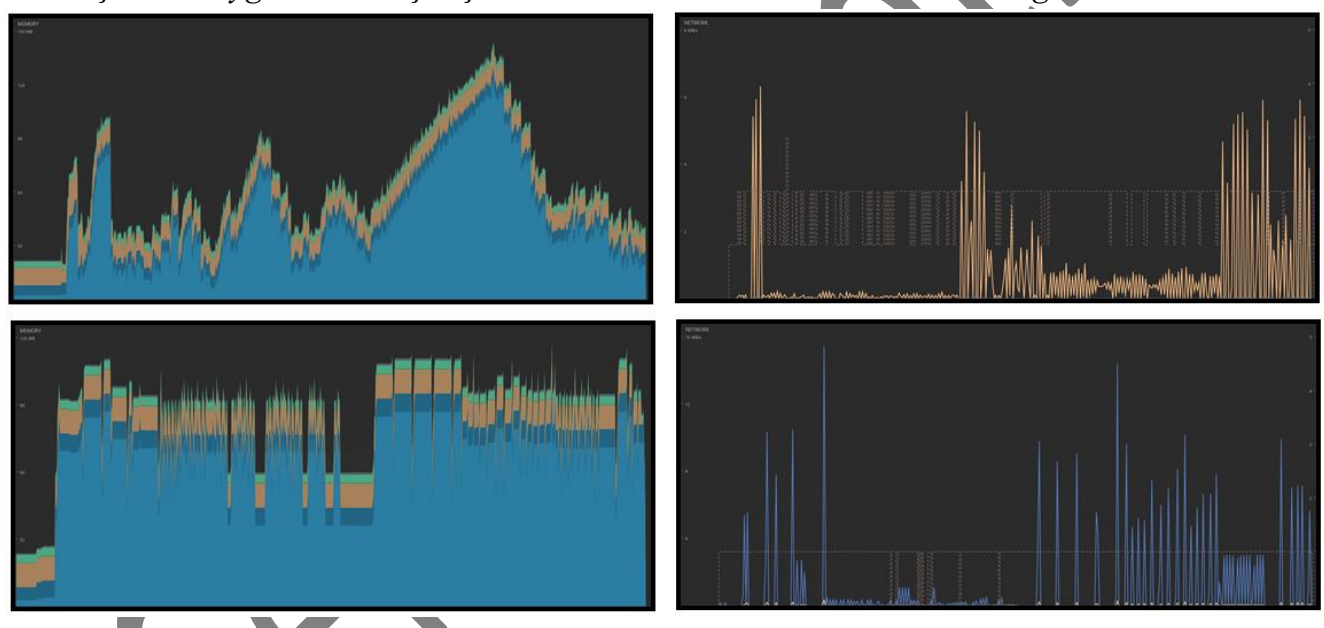

Holocall uygulaması sunucu ve istemci olmak üzere iki farklı kipte çalışabildiğinden değerlendirmeler Tablo 1'de görüldüğü üzere her iki kip için ayrı olarak incelenmiştir.

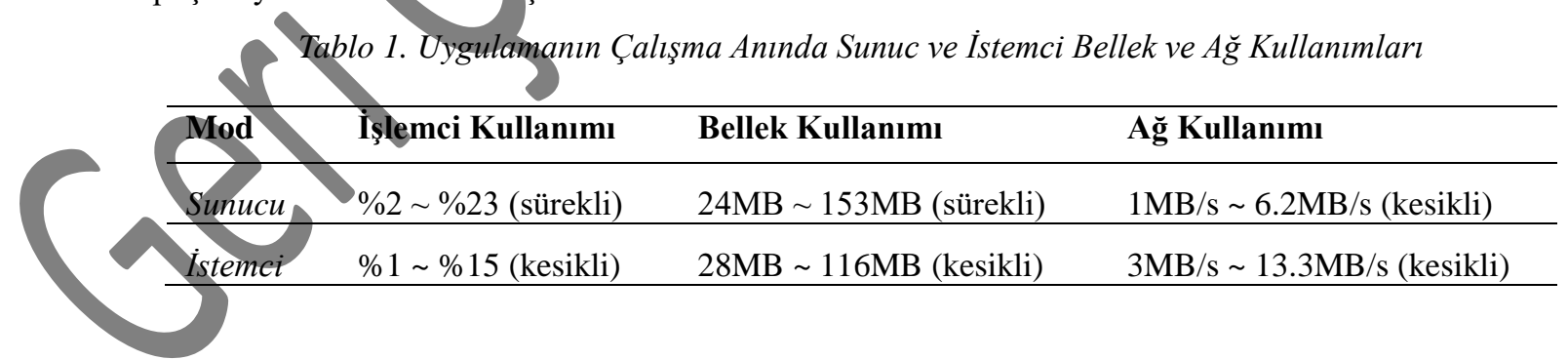

Uygulama veri aktarımı yaparken görüntü dosyalarını tek tek sunucudan istemciye göndermektedir. Bunun yerine video olarak iletim yapılması ile performans artabilirdi ancak bu durumda ekran görüntüsünü video olarak alabilmek için MediaRecorder sınıfı kullanılması gerekmektedir. Android işletim sisteminin bu sınıfla ilgili bir kısıtlaması bulunmaktadır. Eş zamanlı olarak yalnızca bir MediaRecorder objesi çalışabilmektedir ve hem ön hem de arka kamera ile aynı anda video kaydedilememektedir. Günümüzde kullanılan görüntülü görüşme uygulamalarının tamamı bu sınıfı kullandığından dolayı Holocall bu sınıfı kullanılamamakta, dolayısıyla görüntü video olarak kaydedilemiyor veya aktarılamamaktadır.

Hologram teknolojileri günümüzde en çok sahtecilik ve güvenlik uygulamalarında kullanılmaktadır. Bu çalışmada iletişim için kullanımı iiçin bir uygulama geliştirilmiştir. Ancak gelecekte birçok alanda kullanılabilme potansiyeline sahiptir. Örneğin askeri haritalamada, iyileştirilmiş keşifler için tamamen boyutlu holografik görüntülerden faydanılabilir. Holografik savaş alanları askerlerin 
araziyi 3B görmelerinde ve eğitimlerinde kullanılabilir. Ayrıca tıbbi alanda, Manyetik Rezonans Görüntüleme (MR) ve ultrason taramaları 3D hologramlar halinde sunarak öğrencilerin ve cerrahların eğitiminde değerlendirilebilir.

Özellikle 5G teknolojisinin hayatımıza girmesiyle birlikte hologram teknolojisinin hayatımızda yer alması öngörülmektedir. Mobil ağların sıkıştırılmasındaki iyileşme ve artan hızlarla, statik görüntülerle başlayan ve daha sonra dinamiğe ilerleyen holografik iletişimi görmeye başlayacağız. Hologramlar, kurumsal uygulamalar için ölçülemez derecede yararlı olacaktır. Bu sayede günümüzün akıllı telefon uygulamalarından ve yarının arttırılmış gerçekliğe kadar çoğu gelişmiş teknolojilerle tamamen birlikte kullanılacaktır.

\section{Kaynakça}

1. Gabor, D. (1972). Holography, 1948-1971. Science, 177(4046), 299-313.

2. Collier, R. (2013). Optical holography. Elsevier.

3. Greenslade Jr, T. B. (2011). Pepper's Ghost. The Physics Teacher, 49(6), 338-339.

4. Nakashima, F., Kawazoe, N., Emmei, S., Mizutani, Y., Hattori, H., Kadowaki, S., \& Suzuki, K. (2000). U.S. Patent No. 6,141,123. Washington, DC: U.S. Patent and Trademark Office.

5. Yao, A., Cai, D., Hu, P., Wang, S., Sha, L., \& Chen, Y. (2016, October). HoloNet: towards robust emotion recognition in the wild. In Proceedings of the 18th ACM International Conference on Multimodal Interaction (pp. 472-478).

6. Jones, A., McDowall, I., Yamada, H., Bolas, M., \& Debevec, P. (2007). Rendering for an interactive 360 light field display. In ACM SIGGRAPH 2007 papers (pp. 40-es).

7. Ishikawa, T., \& Gitzinger, T. (2011). U.S. Patent No. 8,054,391. Washington, DC: U.S. Patent and Trademark Office.

8. DiMarzio, J. F. (2008). Android. Tata McGraw-Hill Education.

9. Raffy, P., \& Yassa, F. (2006). U.S. Patent No. 7,002,627. Washington, DC: U.S. Patent and Trademark Office.

10. Josefsson, S. (2006). The base16, base32, and base64 data encodings (pp. 1-18). RFC 4648, October.

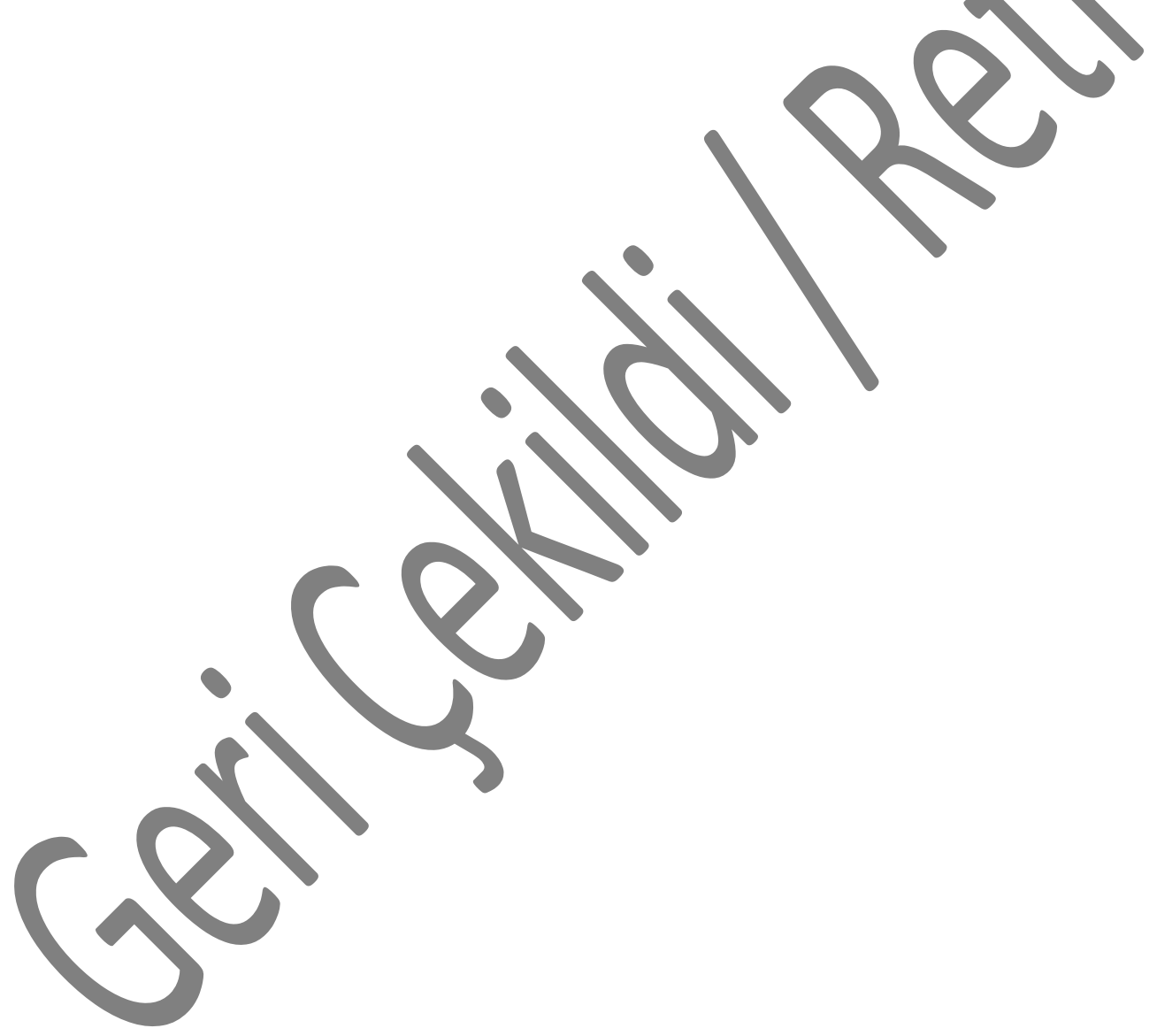

